tance between each member of the ensemble and the proxy record is measured by a cost function using reconstructed and simulated variables at the locations where the proxies are available. The best simulation, defined as the one that minimizes this cost function, is then selected as representative for this particular year or period, and used as the initial condition for the subsequent year. The procedure is repeated as many times as required in order to provide a reconstruction for the whole millennium (e.g., Collins, 2003; Goosse et al., 2006; Figure 1).

In this technique, the model is only constrained locally, at the locations where the proxy records are available. This is a clear advantage, compared to the nudging techniques, as the reconstructed spatial pattern is the result of the data assimilation procedure itself and is thus independent of any statistical method used to reconstruct patterns. A downside of the approach is the potential systematic error incurred if the model is not able to reproduce observed teleconnections between different regions.

Preliminary proofs of concept using this ensemble method have demonstrat- ed that it can efficiently yield a plausible large-scale reconstruction if only a small number of proxies are available, and yet can also reconstruct regional detail where the number of available proxy data are sufficiently large (e.g., Goosse et al., 2006).

On the basis of these successful preliminary results, ongoing work is underway to investigate in greater detail the mechanisms that may be responsible for the climate changes of the past millennium. Potential refinements of the approach include a more sophisticated treatment of the uncertainties in both the proxy data and simulation results. This is a challenging issue for a number of reasons. For example, the nature of the uncertainties in proxy-derived climate records are complex, involving complicated physical or biological responses, which may yield frequency-dependent loss of climate information. Further work is necessary to characterize these uncertainties and biases more fully. Furthermore, classical assimilation methods used in meteorology and oceanography cannot be transferred directly to the analysis of the past millennium. Fortunately, focused efforts in this area are now underway, as discussed at one recent workshop on "Data assimilation to study the climate of the past millennium" (www.astr.ucl.ac.be/index. php?page=Wokshop_assim). It is reasonable to expect that significant improvements in the techniques used for data assimilation over the last millennium will be achieved in the years ahead, yielding significantly refined estimates of past changes and a better understanding of the causes of those changes.

\section{References}

Collins, M., 2003: Quantitative use of paleo-proxy data in global circulation models, Geophysical Research Abstracts, 5: 1-14.

Goosse, H., Renssen, H. Timmermann, A and Bradley, R.S, 2005: Internal and forced climate variability during the last millennium: A model-data comparison using ensemble simulations, Quaternary Science Reviews, 24: 1345-1360.

Goosse H., Renssen, H., Timmermann A., Bradley R.S. and Mann, M.E., 2006: Using paleoclimate proxy-data to select optimal realisations in an ensemble of simulations of the climate of the past millennium, Climate Dynamics, 27: 165-184, D0I 10.1007/ s00382-006-0128-6.

Jones, J. and Widmann, M., 2003: Reconstructing large-scale variability from paleoclimatic evidence by means of Data Assimilation Through Upscaling and Nudging (DATUN). In: Fischer et al. (Eds) The KIHZ project: towards a synthesis of Holocene proxy data and Climate models, Springer, Berlin, 171-193.

van der Schrier, G. and Barkmeijer J., 2005: Bjerknes' hypothesis on the coldness during 1790-1820 AD revisited, Climate Dynamics, 25(5): 537-553.

For full references please consult:

www.pages-igbp.org/products/newsletter/ref2008_2.html

\title{
Facilitating proxy-data interpretation of abrupt climate events using model simulations
}

Ane P. Wiersma ${ }^{1 *}$, D.M. Roche ${ }^{1,2}$ and H. Renssen ${ }^{1}$

'Faculty of Earth and Life Sciences, Vrije Universiteit Amsterdam, The Netherlands; ane.wiersma@falw.vu.nl

2IPSL/Laboratoire des Sciences du Climat et de l'Environnement, Gif-sur-Yvette, France

*Present affiliation: Deltares Subsurface and Groundwater Systems, Utrecht, The Netherlands

\section{Climate model results vs. proxy- based climate reconstructions}

Comparing climate model results for abrupt climate events with proxy-based climate reconstructions is often hampered by the difference in spatial and temporal characteristics. Proxy-based climate reconstructions present a climate signal over a long period of time at a specific location. Due to bioturbation, sample size, aquifer buffering, diffusion, etc., the climate signal recorded at an arbitrary point in time is often the integrated climate signal over several decades. This produces a time series of the climate signal smoothed by a decadalscale filter. Modeling results, on the other hand, are often visualized as the spatial distribution of the average temperature or precipitation over a decadal- or centennial-scale time-window (averaging timewindow) relative to a control climate.

This way of visualizing climate-model results generally gives a good indication of the geographical distribution of the event and the relative magnitude in differ-

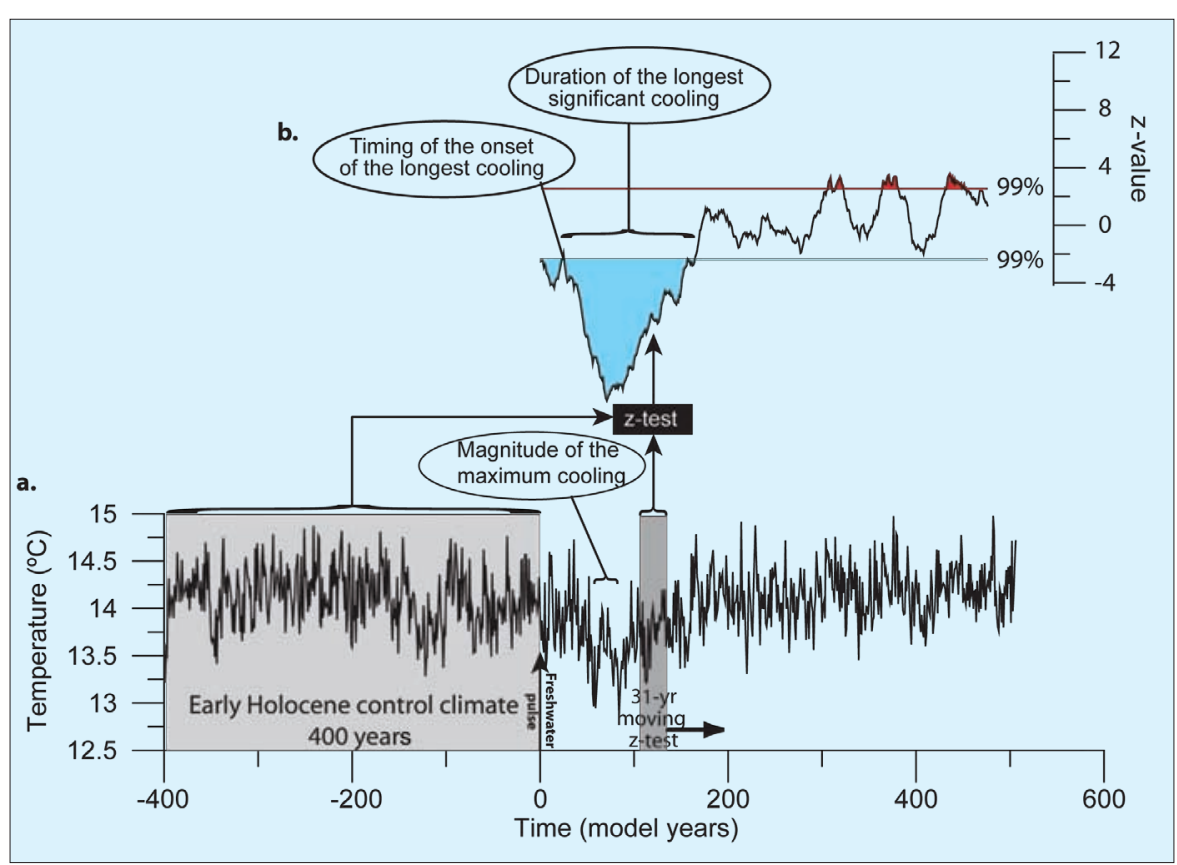

Figure 1: Moving z-test. a) Surface temperature output from a grid-cell in the climate model. The arrow at $t=0$ indicates the introduction of the freshwater pulse. By way of a moving z-test, we assess if the mean of the 31-year moving window is statistically different from the mean of the early Holocene control climate. $\boldsymbol{b}$ ) the z-test values are separated into significant and non-significant values. Also indicated are the variables plotted in Figure 2: Timing of the longest anomalous cooling, duration of the longest anomalous cooling and the maximum 31-year cooling. 
ent areas. However, the method ignores the fact that the climate response in certain areas may have varied on timescales smaller than the applied averaging timewindow, especially when considering relatively short-lived climate anomalies. For instance, areas may have undergone climate changes that were shorter than the averaging time-window, or variability may have occurred within the period, such as a warming preceding a cooling. In these cases, the climate anomaly of a centennial-scale time-window is not a good indication of the climate response in the model. Using shorter averages (e.g., 10-year means) can be misleading, as climate on such a short timescale is influenced by decadal-scale internal variability. Another shortcoming of the use of averaging time-windows is that valuable information present in climate model results is ignored, such as differences in timing and duration of a climate response in different areas.

Here, we propose a novel method for the analysis and presentation of simulation results of anomalous centennial- to millennial-scale climate warming or cooling events. The method provides information on the timing (onset), duration and magnitude of climate events for every spatial grid-cell (5.625 x 5.625 deg. longitude and latitude), similar to the way they could be expressed in proxy-based reconstructions. Information on these factors provides insight into the spatial and temporal evolution of a climate event, and should facilitate a direct comparison between climate models and proxy-based reconstructions. As an illustrative example, we apply the method to climate model results of the 8.2 kyr climate event.

\section{The 8.2 kyr climate event}

The 8.2 kyr event is the most pronounced Holocene climate event in the North Atlantic area (Alley et al., 1997). The event is widely regarded to have been caused by the catastrophic outflow of the proglacial lakes Agassiz and Ojibway, causing weakening of the ocean thermohaline circulation (Barber et al., 1999). In an earlier study, we performed multiple simulations of the $8.2 \mathrm{kyr}$ event in the ECBilt-CLIO-VECODE coupled climate model (Opsteegh et al., 1998; Goosse and Fichefet, 1999; Brovkin et al., 1992) by introducing various volumes of freshwater into the Labrador Sea in a stable early Holocene climate state (Wiersma et al., 2006). One particular experiment, in which we introduced 3.26 $x 10^{14} \mathrm{~m}^{3}$ of freshwater, produced a cooling in Greenland that compared well with the 8.2 kyr event of $\sim 160$ years duration

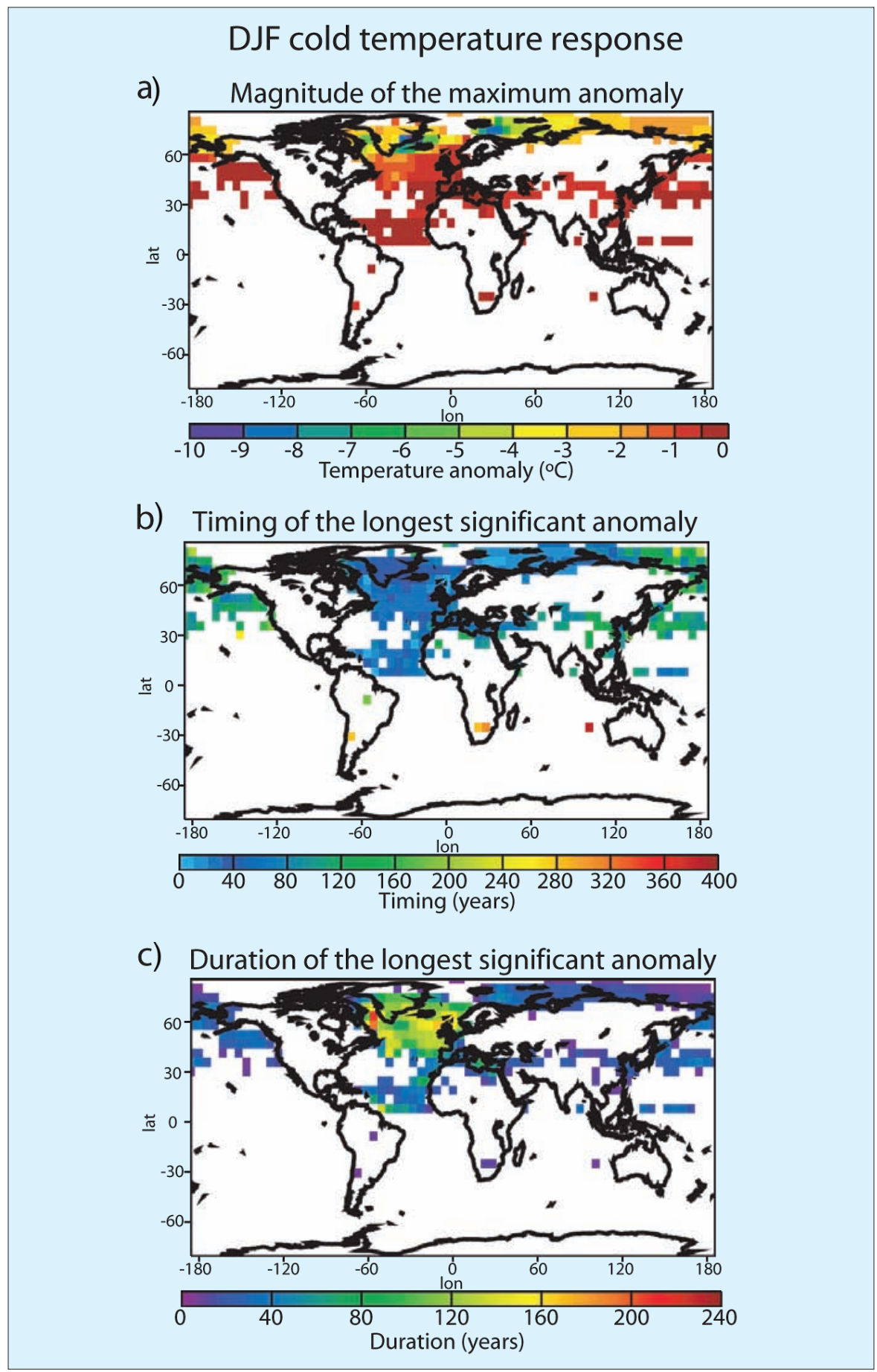

Figure 2: Modeled spatial and temporal characteristics of the significant DJF surface cooling anomaly of the $8.2 \mathrm{kyr}$ event from averaging the results of the 10 ensemble members: $\boldsymbol{a}$ ) maximum 31 -year average cooling; $\boldsymbol{b}$ ) timing of the longest significant cooling; $\mathbf{c}$ ) duration of the longest significant cooling. Notice that the magnitude plot shows the maximum temperature anomaly of the 31-year moving window for every grid-cell that is asynchronous.

(Thomas et al., 2007) and $\sim 3.3^{\circ} \mathrm{C}$ (Kobashi et al., 2007) transient cooling, recorded in Greenland ice cores. This modeling experiment consisted of 10 model runs (ensemble members), each starting from a slightly different climate state. Although the perturbation is applied from different initial conditions, the modeled climate event was similar in each of the different ensemble members.

\section{Analyzing the model results}

We used the surface temperature results of this experiment to analyze the timing, duration and magnitude of the modeled 8.2 kyr event for each model grid-cell. Our atmospheric model contains a surface grid of 64 by 32 cells for longitude and latitude, respectively. In this example (Wiersma et al., 2008), we used the yearly DecemberJanuary-February (DJF) surface temperature output (Fig. 1a).

We are interested in finding the temperature response of the $8.2 \mathrm{kyr}$ event in the model results, as could be expressed in common proxy-based reconstructions. Therefore, in each of the ensemble members we applied a moving z-test to the time-series of surface temperature of every grid-cell. This test assesses whether the mean of a sample (here a 31-year centered moving-window; Fig. 1a) and the popula- 
tion (here the 400 year early Holocene control climate before the perturbation; Fig. 1a) are statistically different, by comparing the variance and average. Subsequently, we separated cold and warm anomalies that are significant at the $99 \%$ level (Fig. $1 \mathrm{~b})$. For the grid-cells with significant cold and/or warm temperature anomalies, we calculated the following properties: the duration of the longest anomaly, the maximum 31-year mean temperature anomaly and the timing of the onset of the longest anomaly relative to the freshwater forcing (Fig. 1).

Applying this method on the separate ensemble members generates a climate response that also includes anomalous data points resulting from natural climate variability. Since we are interested in the temperature anomaly that is forced by the lake drainage, we average the output properties (magnitude, timing and duration) of the 10 ensemble members and mask grid-cells that do not show a significant anomalous response in each ensemble member. Subsequently, we generate anomaly maps for each of the properties. In contrast to many studies that aim to derive the externally forced climate signal (e.g., Stott et al., 2000), we do not first average the ensemble members and then perform the statistical test. The reasoning behind this is that we are interested in the signal that could be registered in climate proxy archives. This signal is comparable to the climate signal of a single ensemble member and different from the artificially enhanced signal of the ensemble average. We then average the properties in the ensemble members and filter out grid-cells that do not show a climate response in each of the ensemble members to obtain the robust response. This step is reasonable because all ensemble members showed a similar climate evolution.

\section{Timing, duration and magnitude}

Figure 2 shows the results of this analysis for the cold response in the DJF season. The first striking feature is that the cold anomaly is concentrated in the northern hemisphere, especially Greenland, the North Atlantic area and its eastern coastline. The Arctic Ocean and the Mediterranean Sea area are affected. A robust cooling response is also present in the Asian subtropical regions around $30^{\circ} \mathrm{N}$. Large variations in magnitude are evident, and the largest anomalies are north of Iceland and near Spitsbergen (Fig. 2a). Furthermore, time-lags in the onset of the event are present in the order of decades (Fig. 2b). Interestingly, the cold response in Greenland emerges ca. 40 years after the freshwater forcing. The duration of the event exhibits geographical variation as well, with the longest duration in the North Atlantic area and gradually decreasing towards the limits of the impact (Fig. $2 \mathrm{c}$ ). In the remaining areas where a response is simulated, the duration is in the order of decades, which strongly reduces the probability of being recorded. Moreover, applying the same analysis on the cold response in the June-July-August season provides insight into seasonal differences in the response. Focusing on the warm response provides information on the behavior of the bipolar seesaw and possible warm overshoots following an initial cooling (Wiersma et al., 2008).

To summarize, the method presented here is an improvement on the traditional analysis of climate modeling results and facilitates model-data comparison for several reasons. First, the method provides information on geographical variation in timing, duration and magnitude of abrupt climate events, which can serve as a framework for proxy-data interpretation. Second, proxy-based climate reconstructions can be compared directly to the modeling output, since the latter contains decadalscale information comparable to proxy records. Third, the results can be used to indicate areas where the event is expected to be registered in proxy records, providing clues about where to look for a specific climate response.

\section{References}

Alley, R.B., Mayewski, P.A., Sowers, T., Stuiver, M., Taylor, K.C. and Clark, P.U., 1997: Holocene Climatic Instability - a Prominent, Widespread Event 8200 Yr Ago, Geology, 25: 483-486.

Kobashi, T., Severinghaus, J.P., Brook, E.J., Barnola, J.-M. and Grachev, A.M., 2007: Precise timing and characterization of abrupt climate change 8200 years ago from air trapped in polar ice, Quaternary Science Reviews, 26: 1212-1222.

Thomas, E.R., Wolff, E.W., Mulvaney, R., Steffensen, J.P., Johnsen, S.J., Arrowsmith, C., White, J.W.C., Vaughn, B. and Popp, T., 2007: The $8.2 \mathrm{ka}$ event from Greenland ice cores, Quaternary Science Reviews, 26: 70-81.

Wiersma, A.P., Renssen, H., Goosse, H. and Fichefet, T., 2006: Evaluation of different freshwater forcing scenarios for the $8.2 \mathrm{ka}$ BP event in a coupled climate model, Climate Dynamics, 27: 831-849.

Wiersma, A.P., Roche, D.M. and Renssen, H., 2008: Fingerprinting the $8.2 \mathrm{ka}$ BP event climate response in a coupled climate model. In: Wiersma, A.P., Character and causes of the 8.2 ka climate event, comparing coupled climate model results and palaeodimate reconstructions, PhD Thesis, VU University Amsterdam, The Netherlands.

For full references please consult:

www.pages-igbp.org/products/newsletter/ref2008_2.html

\title{
PMIP2 climate model-proxy data intercomparisons for the LGM
}

\author{
Bette L. Otto-Bliesner and Esther Brady \\ National Center for Atmospheric Research, Boulder, USA; ottobli@ucar.edu
}

Climate models may perform equally well for simulating the present-day and $20^{\text {th }}$ century climates, yet produce very different responses to likely changes in forcing (such as greenhouse gases and insolation) in the future. Therefore, it is important to compare current state-of-the-art climate model simulations of past climates against the benchmarks of paleo-observations. The Paleoclimate Modelling Intercomparison Project (PMIP) is a long-standing initiative endorsed by PAGES and the World Climate Research Programme JSC/ CLIVAR Working Group on Coupled Models (WGCM). It provides for coordination of paleoclimate modeling activities on the mechanisms of climate change, the identification of key feedbacks operating in the climate system, and on the capability of climate models to reproduce climates that are different from modern.

PMIP initially focused on two periods, the Last Glacial Maximum (LGM; ca. 21 cal kyr BP) and the mid-Holocene $(\mathrm{MH}$; ca. $6 \mathrm{cal} \mathrm{kyr} \mathrm{BP).} \mathrm{The} \mathrm{experiments} \mathrm{were} \mathrm{de-}$ signed to examine the climate response to Milankovitch orbital forcings for the $\mathrm{MH}$ and the presence of large ice sheets and low greenhouse gas (GHG) concentrations for the LGM. Seventeen modeling groups participated in simulations of these time periods with atmosphere-only models (PMIP1), and twelve groups in the second phase of the project (PMIP2) using oceanatmosphere or ocean-atmosphere-vegetation models. With the incorporation of coupled atmosphere-ocean-sea ice models into PMIP2, new comparisons to proxy data can now be used in evaluating the capabilities of current climate models to simulate climate conditions different than present. Here, we describe two such comparisons of the PMIP2 LGM simulations to glacial proxy data: deep-ocean tempera- 